\title{
SERVIÇO NACIONAL DE APRENDIZAGEM DO COOPERATIVISMO: EMANCIPAÇÃO OU SUBORDINAÇÃO?
}

\section{Eduardo Faria Silva}

Mestrando em Direito Cooperativo e Cidadania na Universidade Federal do Paraná - UFPR. Integrante do Núcleo de Direito Cooperativo e Cidadania da Universidade Federal do Paraná - UFPR.

RESUMO: A proposta de análise elucida o alcance dos objetivos prescritos na legislação que instituiu o Serviço Nacional de Aprendizagem do Cooperativismo (SESCOOP), principalmente no tocante à formação do trabalhador em cooperativa. Trabalha-se, assim, com a dissociação entre o pensamento cooperativista e o capitalista, em especial no que se refere ao indivíduo subordinado e aos aparelhos ideológicos de formação, normalização e disciplina para o trabalho.

PALAVRA-CHAVE: Direito cooperativo; Sistema Nacional de Aprendizagem do Cooperativismo; Sociedade disciplinar. 
Quem quer que se disponha a transformar a ordem social terá de enfrentar duas ordens de problemas. Primeiro, conhecer as forças dinâmicas em conjunção, as resistências à mudança e os fatores capazes de ativá-las para, com base nesse conhecimento, fixar a estratégia que deve utilizar. Segundo, melhorar o discurso das vanguardas revolucionárias. Vale dizer, face ao atraso e à penúria, ser capaz de diagnosticar suas causas, denunciar os danos que acarretam e, ainda, prever as possibilidades de progresso contidas em cada situação. ${ }^{1}$

\section{INTRODUÇÃO}

Cândido de Alegre, professor, membro de uma importante família da capital, chega ao trabalho, pontualmente, às 7 horas e 30 minutos, e constata que, Eles, colocaram duas filmadoras na sala de aula em que trabalha e na sala de atendimento aos alunos. Naquele momento, pensa rapidamente: "O sistema de monitoramento por câmeras de vídeo foi uma grande idéia, sinto-me mais seguro neste espaço."

No dia seguinte, Cândido é surpreendido por o novo sistema de controle de freqüência dos professores. O velho cartão-ponto de papel foi substituído por um leitor ótico de última geração, que fica na entrada do prédio. Novamente, reflete: "Agora temos a segurança de que os nossos dados não serão extraviados e que aqueles atrasados não poderão pedir para outros baterem o cartão-ponto. Finalmente, a igualdade!"

No final do mês observa, cuidadosamente, seu contracheque e fica alegremente surpreendido que, em vez de constar o termo empregado no documento, aparece a expressão colaborador. De plano, pega o formulário de sugestões na sala dos professores e escreve eufórico: "Parabéns pela nobre iniciativa". Ao sair do trabalho, em um belo ônibus da Universidade, que o deixa na porta de casa, declara, com leve sorriso, em voz baixa: "Finalmente, Eles, reconheceram que uma nova relação deveria ser estabelecida entre a direção e o

\footnotetext{
${ }^{1}$ RIBEIRO, Darcy. O Dilema da América Latina. Petrópolis: Vozes, 1978. p. 18 e 19.
} 
corpo funcional, ou seja, já era tempo de ser firmado um novo pacto entre Eles e os que produzem."

Eles ao lerem o formulário de no 13.666, na reunião de avaliação semanal, destacam em tom irônico: "Todos leram a carta do trabalhador nํ II-5-3.071?" O outro replica com outra pergunta: "Que trabalhador?" A palavra volta ao relator: "Viram como conseguimos, mais um explorado, dominado e sujeitado, mas alegre."

Vista por outro ângulo a situação quase-anedótica, pode-se afirmar que a atual fase de desenvolvimento do capitalismo possibilitou a constituição de um espaço de in-transparência, em que foi possível penetrar na essência do indivíduo e fazer com que ele não perceba mais sua posição nas relações sociais.

Essa in-transparência se apresenta de várias formas. No caso do trabalhador, por exemplo, revela-se por sua completa incapacidade de perceber a dimensão do seu trabalho e, por conseqüência, agir como trabalhador. O trabalhador deixa de ser trabalhador para ser, ao sonho de qualquer administrador renegado, colaborador de uma empresa capitalista.

As formas de controle exercidas sobre os sujeitos e, conseqüentemente, a construção da subjetividade dos indivíduos, a partir de algumas reflexões sobre os objetivos do Serviço Nacional de Aprendizagem do Cooperativismo - SESCOOP, instituído Medida Provisória no $1.715,{ }^{2}$ de 03 de setembro de 1998, e o Decreto ํo 3.017, de 06 de abril de 1999, pode-se inserir nessa perspectiva de análise.

O conteúdo estruturante dos objetivos do SESCOOP aponta para uma direção diametralmente oposta à construção histórica do cooperativismo, ao constituir-se e ampliar-se financeiramente com a presença de trabalhadores subordinados em cooperativas.

A proposta de análise, de outra parte, está relacionada com a concepção do movimento cooperativista fundamentado em práticas e estruturas anti-hegemônicas de "natureza emancipatória, libertadora e humanizante", ${ }^{3}$ e com as ações políticas que adotam idêntico direcionamento.

Entende-se que a construção de um sistema cooperativo requer, por princípio, o fortalecimento dos movimentos emancipatórios dos trabalhadores para que passem da condição de subalternos à condição de atuantes autônomos e

\footnotetext{
${ }^{2}$ A última reedição da Medida Provisória foi a de nํㅜ․168-39, de 26 de julho de 2001.
} 
dominantes, pois "as cooperativas são pacientes focos de uma resistência activa [sic] ao que há de anti-humano no presente, susceptíveis de nos ajudarem a antever o que o mundo poderá ser no futuro". ${ }^{4}$

Trabalha-se, assim, com a dissociação entre o pensamento cooperativista e o capitalista, em especial, no que se refere ao indivíduo subordinado e aos aparelhos ideológicos de formação para o trabalho.

\section{DO IDEÁRIO COOPERATIVISTA AOS OBJETIVOS DO SESCOOP}

O projeto cooperativista instaurado, a partir da gênese da cooperação moderna, fundação da Rochdale Society of Equitable Pioneers, tem por objetivo finalístico a transformação da sociedade orientada por valores capitalistas. As cooperativas, na realidade, "podem ser olhadas como um meio de transformação social, quer pela energia libertadora que incorporam, quer pela eficácia prática quotidiana revelada". ${ }^{5}$

Os elementos que integram o pensamento e o agir do movimento cooperativista apontam para a emancipação do trabalhador frente ao capital, sendo o fortalecimento da cooperação a essência da estratégia adotada para superação da exploração. ${ }^{6}$

As ações políticas e jurídicas visando à consolidação do cooperativismo devem, neste prisma, considerar e incorporar os elementos ora apresentados, em especial, o aspecto referente à emancipação da exploração exercida pelo capitalismo.

No caso brasileiro, destaca-se o papel do Serviço Nacional de Aprendizagem do Cooperativismo - SESCOOP, mediante a edição da Medida Provisória $n^{0} 1.715,{ }^{7}$ de 03 de setembro de 1998, e o Decreto ํㅜ 3.017, de 06 de abril de 1999, constituído, no governo do Presidente Fernando Henrique Cardoso.

À entidade foi atribuída personalidade jurídica de direito privado, composta por entes vinculados ao sistema sindical, sem prejuízo de fiscalização pelo Tribunal

${ }^{3}$ NAMORADO, Rui. Horizonte Cooperativo: Política e Projeto. Coimbra: Almedina, 2001. p. 06.

4 Ibidem p. 06.

5 NAMORADO, Rui. Introdução ao Direito Cooperativo: Para uma Expressão Jurídica da Cooperatividade. Coimbra: Almedina, 2000. p. 13 e 14.

${ }^{6}$ NAMORADO, Rui. Horizonte Cooperativo: Política e Projeto. Coimbra: Almedina, 2001. p. 43. 
de Contas da União, tendo por objetivo organizar, administrar e executar, em todo território nacional, o ensino de formação profissional, desenvolvimento e promoção social do trabalhador em cooperativas e dos cooperados (artigo 8ํ da MP).

A direção do SESCOOP foi composta por um Conselho Nacional, com a seguinte representação: a) um membro do Ministério do Trabalho; b) um membro do Ministério da Previdência e Assistência Social; c) um membro do Ministério da Fazenda; d) um membro do Ministério do Planejamento, Orçamento e Gestão; e) um membro do Ministério da Agricultura e do Abastecimento; f) cinco membros da Organização das Cooperativas Brasileiras - OCB; ${ }^{8}$ e g) um membro dos trabalhadores em sociedades cooperativas. A presidência da entidade foi concedida ao Presidente da OCB, o qual tem direito, nas deliberações, somente a voto de qualidade (artigo 9ำ da MP).

As receitas do SESCOOP são oriundas de diversas fontes, tais como: a) doações e legados; b) subvenções voluntárias da União, dos Estados, do Distrito Federal e dos Municípios; c) rendas oriundas de prestação de serviços, da alienação ou da locação de seus bens; d) receitas operacionais; e) penas pecuniárias; e f) contribuição compulsória incidente sobre a remuneração dos empregados das cooperativas (artigo 10ำ da MP).

A principal receita, com efeito, é constituída pela contribuição mensal compulsória recolhida pela Previdência Social, no percentual de 2,5\% (dois vírgula cinco por cento), sobre o montante da remuneração paga a todos os empregados das cooperativas (inciso I do artigo 10ํ da MP). Como se vê, admite-se e privilegiase o trabalho subordinado no âmbito das cooperativas.

A contribuição foi instituída em substituição aos tributos devidos e recolhidos pelas sociedades cooperativas, destinadas ao: a) Serviço Nacional de Aprendizagem Industrial - SENAI; b) Serviço Social da Indústria - SESI; c) Serviço Nacional de Aprendizagem Comercial - SENAC; d) Serviço Social do Comércio SESC; e) Serviço Nacional de Aprendizagem do Transporte - SENAT; f) Serviço

\footnotetext{
${ }^{7}$ A última reedição da Medida Provisória foi a de nํㅜ․168-39, de 26 de julho de 2001.
}

${ }^{8} \mathrm{O}$ artigo segundo do Estatuto da OCB dispõe: "Art. 2 - À ORGANIZAÇÃO DAS COOPERATIVAS BRASILEIRAS compete: s) exercer a representação sindical patronal das cooperativas, assumindo todas as prerrogativas de Confederação Patronal." Disponível em: <http://www.ocb.org.br> Acesso em: 15 dezembro de 2004. 
Social do Transporte - SEST; e g) Serviço Nacional de Aprendizagem Rural SENAR ( $2^{\circ}$ do artigo $10^{\circ}$ da MP).

Visualizado o histórico normativo dessa nova entidade integrante do sistema "S", cabe efetuar algumas ponderações à consolidação jurídica instituída pela Medida Provisória e o Decreto, ambos acima mencionados, a fim de compreender os propósitos estruturantes constantes nas prescrições legais, isto é, ultrapassar a aparência do conteúdo e penetrar no espírito da norma produzida.

Acredita-se que a centralidade da análise deve ser focada nos objetivos estipulados para o SESCOOP, pois fazem transparecer a essência da quimera, isto é, os verdadeiros propósitos da entidade. Adotando-se o critério proposto, constatase que cabe ao SESCOOP gerenciar todo processo de formação e qualificação dos trabalhadores em cooperativas e dos cooperados.

Contudo, questiona-se, inicialmente, se é condizente com os valores e princípios cooperativos a existência de trabalhadores contratados em cooperativas e, ainda, se é papel das entidades cooperativas prepará-los para o trabalho subordinado, ao invés de qualificá-los para a autogestão? Por outro viés, pergunta-se se é condizente com os valores e princípios cooperativos que o Serviço Nacional de Aprendizagem do Cooperativismo SESCOOP seja financiado por contribuições oriundas do desconto previdenciário dos trabalhadores em cooperativas? Sob outro prisma, indaga-se se é condizente com os valores e princípios cooperativos que o Serviço Nacional de Aprendizagem do Cooperativismo - SESCOOP seja presidido por uma entidade que representa a classe patronal?

Posicionando-se de forma positiva aos questionamentos, evidencia-se um consentimento e fomento à existência de trabalhadores empregados em cooperativas e a existência de um serviço que tem por finalidade a formatação do indivíduo para o trabalho subordinado, fato que contraria diretamente a lógica emancipatória do sistema cooperativo e aponta para a docilização e não para a autonomia dos trabalhadores.

Michel Foucault, em Vigiar e Punir', demonstra o surgimento, no Ocidente, do poder disciplinar, de vigilância, controle e correção, ou seja, aquele poder que tornou, de alguma forma, a sociedade programada e que fabricou "corpos submissos e exercitados, corpos dóceis". ${ }^{10}$

\footnotetext{
${ }^{9}$ FOUCAULT, Michel. Vigiar e Punir.Petrópolis: Vozes, 2004.

${ }^{10}$ Ibidem p. 119.
} 
A teoria do direito penal, conduzida por Beccaria, que previa a punição, apenas para os casos de existência de uma lei explícita, se opõe completamente à panoptista (o panóptico é um modelo de construção idealizado por Bentham e que permite a teoria do poder disciplinar de Foucault ${ }^{11}$ ) em que a vigilância sobre os indivíduos se exerce no nível não do que se faz, mas do que se é; não do que se faz, mas do que se pode fazer. ${ }^{12}$

O panoptismo, analisado por Foucault, espraia-se e capilariza-se no "quotidiano de instituições que enquadram a vida e os corpos dos indivíduos"13, tendo, desse modo, a capacidade de penetrar na "existência individual" 14 . A experiência panoptista que transcorreu na França, nas chamadas fábricas-prisão, entre os anos de 1840 a 1845 , demonstra qual a funcionalidade e instrumentalidade do sistema:

Era uma instituição onde havia 400 pessoas que não eram casadas e que deviam levantarse todas as manhãs às cinco horas; às cinco e cinqüenta deveriam ter terminado de fazer a toilette, a cama e ter tomado o café; às seis horas começava o trabalho obrigatório, que terminava às oito e quinze da noite com uma hora de intervalo para o almoço; às oito e quinze, jantar, oração coletiva; o recolhimento aos dormitórios era às nove horas em ponto. O domingo era um dia especial; o artigo cinco do regulamento desta instituição dizia: 'Queremos guardar o espírito que o domingo deve ter, isto é, dedicá-lo ao cumprimento do dever religioso e ao repouso. Entretanto, como o tédio não demoraria a tornar o domingo mais cansativo do que os outros dias da semana, deverão ser feitos exercícios diferentes, de modo a passar este dia cristão e alegremente'; de manhã, exercícios religiosos, em seguida exercícios de leitura e de escrita e finalmente recreação às últimas horas da manhã; à tarde, catecismo, as vésperas, e passeio depois das quatro horas, se não fizesse frio. Caso fizesse frio, leitura em comum. Os exercícios religiosos e a missa não eram assistidos na igreja próxima porque isso permitiria aos pensionistas deste estabelecimento terem contato com o mundo exterior; assim, para que nem mesmo a igreja fosse o lugar ou o pretexto de um contato com o mundo exterior, os serviços religiosos tinham lugar em uma capela construída no interior do estabelecimento. 'A igreja paroquial, diz ainda este

11 "O princípio é conhecido: na periferia uma construção em anel; no centro, uma torre; esta é vazada de largas janelas que se abrem sobre a face interna do anel; a construção periférica é dividida em celas, cada uma atravessando toda a espessura da construção; ela têm duas janelas, uma para o interior, correspondendo às janelas da torre; outra que dá para o exterior, permite que a luz atravesse a cela lado a lado. Basta então colocar um vigia na torre central, e em cada cela trancar um louco, um doente, um condenado, um operário ou um escolar". (FOUCAULT, Michel. Vigiar e Punir.Petrópolis: Vozes, 2004, p. 166-167).

${ }^{12}$ FOUCAULT, Michel. As Verdades e as formas jurídicas. Rio de Janeiro: Nau, 2001, p. 104.

13 Ibidem p. 107.

14 Ibidem p. 107. 
regulamento, poderia ser um ponto de contato com o mundo e por isso uma capela foi consagrada no interior do estabelecimento'. Os fiéis de fora não eram sequer admitidos. Os pensionistas só podiam sair do estabelecimento durante os passeios de domingo, mas sempre sob a vigilância do pessoal religioso. Este pessoal vigiava os passeios, os dormitórios e assegurava a vigilância e exploração das oficinas. $O$ pessoal religioso garantia, portanto, não só o controle do trabalho e da moralidade, mas também o controle econômico. Estes pensionistas não recebiam salários, mas um prêmio - uma soma global estipulada entre 40 e 80 francos por ano - que somente lhes era dado no momento em que saiam. No caso de uma pessoa de outro sexo precisar entrar no estabelecimento por razões materiais, econômicas e etc, deveria ser escolhido com o maior cuidado e permanecer por muito pouco tempo. O silêncio lhes era imposto sob pena de expulsão. De um modo geral, os dois princípios de organização, segundo o regulamento, eram: os pensionistas nunca deveriam ficar sozinhos no dormitório, no refeitório, na oficina, ou no pátio, e deveria ser evitada qualquer mistura com o mundo exterior, devendo reinar no estabelecimento um único espírito.

Que instituição era esta? No fundo a questão não tem importância, pois poderia ser indiferentemente qualquer uma: uma instituição para homens ou para mulheres, para jovens ou para adultos, uma prisão, um internato, uma escola ou uma casa de correção. Não é hospital, pois, fala-se muito em trabalho. Também não é um quartel, pois se trabalha. Poderia ser um hospital psiquiátrico, ou qualquer casa de tolerância. Na verdade, era simplesmente uma fábrica. Uma fábrica de mulheres que existia na região do Ródamo e que comportava quatrocentas operárias. ${ }^{15}$

O funcionalismo produtivista se utiliza desses instrumentos e desenvolve formas de controle que sejam mais sutis, menos visíveis e menos onerosas ao sistema, porém que garantam maior eficácia de resultados em prol dos seus interesses. As estruturas de produção organizadas em fábricas-prisão, hospitaisprisão, escolas-prisão, dão lugar, na presente fase de desenvolvimento do capital, às firmas-rede, em que os processos de qualificação, de capacitação e os controles da produção e dos fluxos financeiros podem ser monitorados à distância, em tempo real.

As firma-redes escolhem estrategicamente seus núcleos de competências (p. ex. concepção e montagem do bem), fracionando com as outras empresas as demais fases da produção e comercialização do produto.

\footnotetext{
15 Ibidem p. 108 e 109.
} 
Uma montadora de carros americana, por exemplo, pode produzir peças para um veículo em diversos países e ter o total controle sobre a qualidade do bem produzido, sendo os selos de qualidade (ISO) um dos mecanismos utilizados para garantir as características do bem.

Assim como os processos de industrialização transformaram a agricultura e a tornaram mais produtiva, a revolução da informática transformará a indústria, redefinindo e rejuvenescendo processos de fabricação. ${ }^{16}$

Estes novos modelos exigem a alteração do formato de organização da força de trabalho. A imagem do trabalho assalariado clássico cede espaço para os trabalhadores de empresas terceirizadas, trabalhadores temporários ou colaboradores, como o personagem Cândido de Alegre, fato que, por sua vez, requer a existência de serviços que façam a formação e qualificação dos trabalhadores para atenderem as novas necessidades do capital.

Francisco de Oliveira afirma que a última transformação no setor de produção revolucionou as relações de trabalho, ou seja, que houve uma radicalização do trabalho abstrato, verbis:

Avassalada pela Terceira Revolução Industrial, ou molecular-digital, em combinação com o movimento da mundialização do capital, a produtividade do trabalho dá um salto mortal em direção à plenitude do trabalho abstrato. ${ }^{17}$

Transpondo-se o conteúdo da argumentação suscitada ao presente caso, nota-se que formar e qualificar trabalhadores de cooperativas, por meio, ainda, da contribuição incidente sobre o montante da remuneração deles, é fortalecer o modo de produção capitalista e ratificar, conseqüentemente, a lógica do modelo que necessita que "o tempo dos homens seja oferecido ao aparelho de produção; que o aparelho de produção possa utilizar o tempo de vida, tempo de existência dos homens", pois é "desta forma que o controle se exerce."18

Nessa conjuntura, a perpetuação de empregados em cooperativas vinculase as duas necessidades estruturantes da sociedade industrial, ou seja, de ter o tempo dos homens posto no "mercado, oferecido aos que querem comprar, e

\footnotetext{
${ }^{16}$ NEGRI, Antonio; HARDT, Michael. Império. Rio de Janeiro: Editora Record, 2001. P. 306 e 307.

17 OLIVEIRA, Francisco. Crítica à razão dualista o ornitorrinco. $1^{\underline{a}}$ ed. São Paulo: Boitempo Editorial,
} 2003. P. 135.

${ }^{18}$ FOUCAULT, Michel. A Verdade e as Formas Jurídicas. Rio de Janeiro: Nau Editora, 2001. p. 116. 
comprá-lo em troca de um salário" e, "por outro lado, que este tempo dos homens seja transformado em tempo de trabalho. É por isso que em uma série de instituições encontra-se o problema e as técnicas da extração máxima do tempo."19

Todavia, a existência de trabalhadores subordinados em cooperativas contraria a própria essência do sistema que busca a emancipação do indivíduo à exploração exercida pelo modelo de produção atualmente hegemônico.

Ter um serviço ao dispor do cooperativismo que organize, administre e execute, em todo território nacional, o ensino de formação profissional, desenvolvimento e promoção social do trabalhador em cooperativa e dos cooperados, correspondem a idéia do corpo que deve ser "formado, reformado, corrigido, o que deve adquirir aptidões, receber um certo número de qualidades, qualificar-se como um corpo capaz de trabalhar" ${ }^{20}$, isto é, fazer que o corpo transforme-se em força de trabalho.

\section{CONSIDERAÇÕES FINAIS}

O personagem Cândido não é um ser individualizado e isolado, ao contrário, representa parcela significativa da classe trabalhadora que está encoberta pela atual in-transparência produzida pelo estamento capitalista, que possibilitou cooptar e neutralizar parcela significativa dos trabalhadores e dos intelectuais.

Qual o efeito disso? Somente a convenção tempo irá possibilitar a analise histórica dos efeitos do desequilíbrio de forças existentes. No entanto, os atores sociais que compreendem que o modelo econômico hegemonicamente vigente tem uma mecânica estrutural excludente e pretendem transformar a ordem social posta, devem ter clareza do conteúdo de suas ações.

O cooperativismo apresenta-se como uma das alternativas para superação da exploração do indivíduo frente ao capital, tendo em vista que, por exemplo, a propriedade dos meios de produção é coletiva e o direcionamento da sociedade apresenta-se de forma autogestionária.

Entretanto, a superação do capitalismo é longa e demorada, sendo que as experiências que o contrapõem não são modelos acabados. O desenvolver do

19 Ibidem p. 116. 
processo de transformação sinaliza os ajustes que devem ser feitos, cabendo aos agentes envolvidos interpretá-los e aplicá-los corretamente.

O capital tem a necessidade de controle total da subjetividade dos indivíduos para oferecer a energia destes como força de trabalho. Cientes dessa operação cabe aos atores que buscam a transformação barrarem e contraporem tal movimento, principalmente, se a ação do capital encontra-se nas estruturas construídas para superá-lo.

Neste sentido, incentivar a criação do Serviço Nacional de Aprendizagem do Cooperativismo (SESCOOP) para que faça a formação profissional, desenvolvimento e promoção social do trabalhador em cooperativa é agir de forma diametralmente oposta ao ideário cooperativista, pois permite que, na estrutura cooperativa possa extrair-se a mais valia do trabalhador assalariado.

Redirecionar o desvio existente é cogente e necessário, sob pena de observar a cooptação da estrutura pelo capital e ver ratificada o pensamento foucaultiano de que "há duas espécies de utopia: as utopias proletárias socialistas que têm a propriedade de nunca se realizarem, e as utopias capitalistas que têm a má tendência de se realizarem freqüentemente". ${ }^{21}$

\section{BIBLIOGRAFIA}

FOUCAULT, Michel. Vigiar e Punir.Petrópolis: Vozes, 2004.

FOUCAULT, Michel. As Verdades e as formas jurídicas. Rio de Janeiro: Nau, 2001.

GEDIEL, José Antônio, (Org.). Os Caminhos do Cooperativismo. Paraná: Editora UFPR, [s.d.].

NAMORADO, Rui. Horizonte Cooperativo: Política e Projeto. Coimbra: Almedina, 2001.

NAMORADO, Rui. Introdução ao Direito Cooperativo: Para uma Expressão Jurídica da Cooperatividade. Coimbra: Almedina, 2000.

NEGRI, Antonio; HARDT, Michael. Império. Rio de Janeiro: Editora Record, 2001.

OLIVEIRA, Francisco. Crítica à razão dualista o ornitorrinco. São Paulo: Boitempo Editorial, 2003.

RIBEIRO, Darcy. O Dilema da América Latina. Petrópolis: Vozes, 1978.

SINGER, Paul. Introdução à Economia Solidária. São Paulo: Editora Fundação Perseu Abramo, 2002.

\footnotetext{
20 Ibidem p. 119.

21 Ibidem p. 110.
} 
